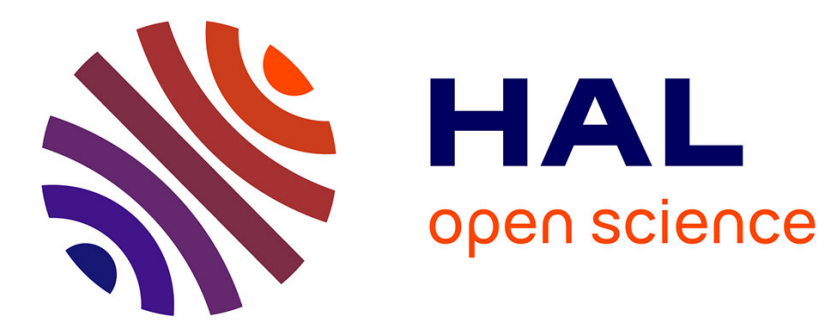

\title{
Horizontal displacement of carbon associated with agriculture and its impacts on atmospheric CO 2
}

\author{
P. Ciais, P. Bousquet, A. Freibauer, T. Naegler
}

\section{To cite this version:}

P. Ciais, P. Bousquet, A. Freibauer, T. Naegler. Horizontal displacement of carbon associated with agriculture and its impacts on atmospheric CO 2. Global Biogeochemical Cycles, 2007, 21 (2), pp.GB2014. 10.1029/2006gb002741 . hal-02924924

\section{HAL Id: hal-02924924 \\ https://hal.science/hal-02924924}

Submitted on 6 May 2021

HAL is a multi-disciplinary open access archive for the deposit and dissemination of scientific research documents, whether they are published or not. The documents may come from teaching and research institutions in France or abroad, or from public or private research centers.
L'archive ouverte pluridisciplinaire HAL, est destinée au dépôt et à la diffusion de documents scientifiques de niveau recherche, publiés ou non, émanant des établissements d'enseignement et de recherche français ou étrangers, des laboratoires publics ou privés. 


\title{
Horizontal displacement of carbon associated with agriculture and its impacts on atmospheric $\mathrm{CO}_{2}$
}

\author{
P. Ciais, ${ }^{1}$ P. Bousquet, ${ }^{1,2}$ A. Freibauer, ${ }^{3}$ and T. Naegler ${ }^{1,4}$ \\ Received 27 April 2006; revised 19 October 2006; accepted 15 January 2007; published 23 May 2007.
}

[1] The growth of crops represents a sink of atmospheric $\mathrm{CO}_{2}$, whereas biomass is consumed by humans and housed animals, yielding respiratory sources of $\mathrm{CO}_{2}$. This process induces a lateral displacement of carbon and creates geographic patterns of $\mathrm{CO}_{2}$ sources and sinks at the surface of the globe. We estimated the global carbon flux harvested in croplands to be $1290 \mathrm{TgC} / \mathrm{yr}$. Most of this carbon is transported into domestic trade, whereas a small fraction (13\%) enters into international trade circuits. We then calculated the global patterns of $\mathrm{CO}_{2}$ fluxes associated with food and feedstuff trade, using country-based agricultural statistics and activity maps of human and housed animal population densities. The $\mathrm{CO}_{2}$ flux maps show regional dipoles of sources and sinks in Asia and North America. The effect of these fluxes on atmospheric $\mathrm{CO}_{2}$ was simulated using a global atmospheric transport model. The mean latitudinal $\mathrm{CO}_{2}$ gradients induced by the displacement of crop products are fairly small $(\approx 0.2 \mathrm{ppm})$ compared with observations (4-5 ppm), indicating that this process has a only a small influence in explaining the latitudinal distribution of $\mathrm{CO}_{2}$ fluxes. On the other hand, the simulated longitudinal mean atmospheric $\mathrm{CO}_{2}$ gradients at northern midlatitudes ( $\approx$ up to $0.5 \mathrm{ppm}$ ) are comparable to the ones measured between atmospheric stations, suggesting that $\mathrm{CO}_{2}$ fluxes from crop products trade are an important component of continental- and regional-scale $\mathrm{CO}_{2}$ budgets. Thus they should be accounted for as prior information in regional inversions.

Citation: Ciais, P., P. Bousquet, A. Freibauer, and T. Naegler (2007), Horizontal displacement of carbon associated with agriculture and its impacts on atmospheric $\mathrm{CO}_{2}$, Global Biogeochem. Cycles, 21, GB2014, doi:10.1029/2006GB002741.

\section{Introduction}

[2] Croplands cover $18 \mathrm{Mkm}^{2}$ of the Earth's surface, roughly $12 \%$ of the land surface [Leff et al., 2004]. Crop primary productivity (NPP) is driven by climate and by human practice including irrigation, fertilizers, and species selection. Cultivated plants species differ from natural ones in their phenology, carbon allocation, productivity, nutrient use, etc. Litter incorporation in the soil and decomposition of soil organic matter are also greatly determined by practice, including tillage, fertilizers, and burning of crop residues. The role of croplands in the terrestrial carbon cycle has received an increasing level of study, which has stimulated their inclusion in global vegetation models [Kucharik, 2003; Gervois et al., 2004]. The carbon sequestration potential of agro-ecosystems is also the object of many studies [e.g., Freibauer et al., 2004; Paustian et al., 2000]. We study here the implications for the global carbon

\footnotetext{
${ }^{1}$ Laboratoire des Sciences du Climat et de l'Environnement, CE Orme des Merisiers, Gif sur Yvette, France.

${ }^{2}$ Université de Versailles St Quentin en Yvelines, Versailles, France.

${ }^{3}$ Max-Planck-Institute for Biogeochemistry, Jena, Germany.

${ }^{4}$ Now at Institut für Umweltphysik, Universität Heidelberg, Heidelberg, Germany.
}

Copyright 2007 by the American Geophysical Union. 0886-6236/07/2006GB002741 cycle of the appropriation and consumption of crop products by humans.

[3] Since the rise of agriculture in the Fertile Crescent around 8500 B.C., human communities have relied on croplands to supply food and fibers. Wherever food supply and demand were not in balance in terms of quality or quantity, trade occurred. For instance during the Roman Empire, it is estimated that $30 \%$ of the wheat used in Italy came from the Nile delta in Egypt [Morgan, 1980]. The need for arable land alters land cover, a process which dramatically accelerated over the past 100 years in response to increasing population [Houghton, 2003; Pointing, 1991]. Not only did the area of croplands increase, the yield of crops in response to more efficient agricultural practice increased as well. For instance, the global harvest of cereals increased by $130 \%$ in the past 40 years, while the corresponding area only increased by $4 \%$.

[4] Imhoff et al. [2004] estimated that 14 to $26 \%$ of the global terrestrial NPP was used by humans for wood, paper, food and feedstuff [see also Vitousek et al., 1986]. Here we study the implications of crop NPP use for the global carbon cycle. The crop products are generally transported by trade before consumption, inducing a lateral flux of carbon and altering the distribution of $\mathrm{CO}_{2}$ fluxes exchanged with the atmosphere. Figure 1 illustrates this flow of carbon. On an annual basis, the crop fields are net sinks of atmospheric 


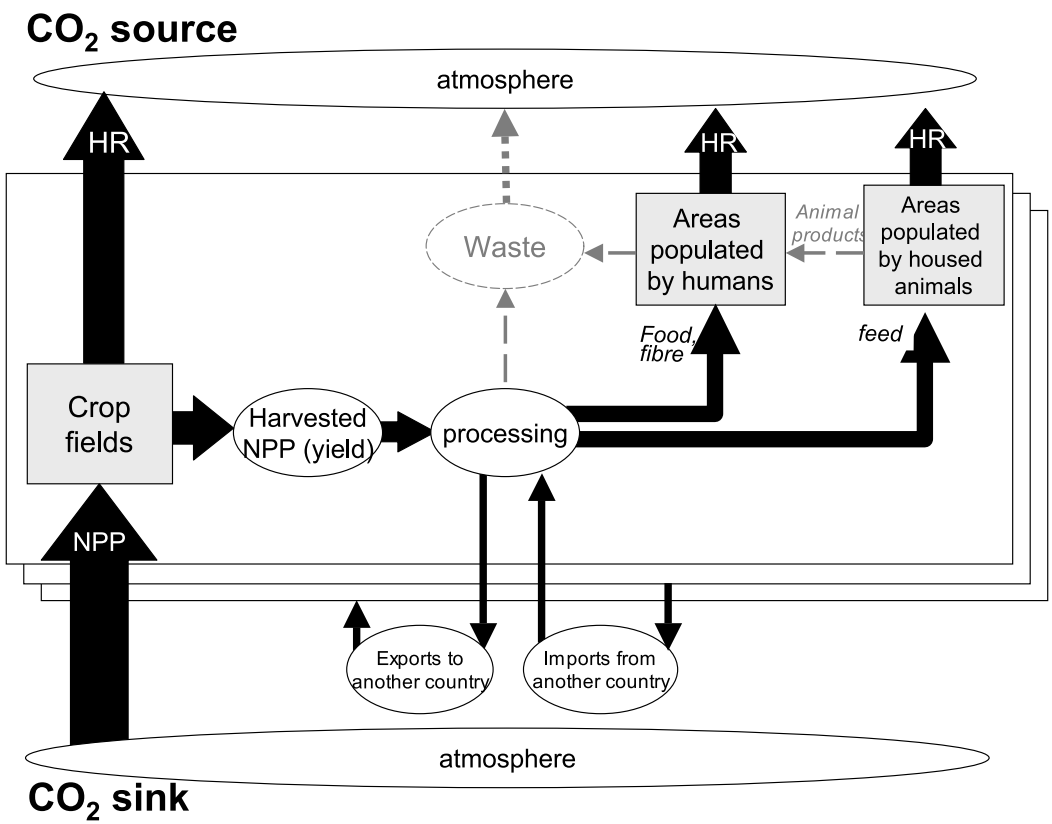

Figure 1. Agricultural carbon displacement inducing $\mathrm{CO}_{2}$ sources and sinks. Within each country, a fraction of atmospheric $\mathrm{CO}_{2}$ sinking in crop fields (NPP) is harvested and then processed, transported, and eventually consumed. The consumption releases $\mathrm{CO}_{2}$ back to the atmosphere as part of the heterotrophic respiration flux (HR on the right side). The nonharvested fraction of crop NPP is decomposed by soil microbes in the ecosystem (HR on the left side). The carbon fluxes due to waste displacement, food and feed storage, and animal products are shown in gray. They are neglected in the study because of their negligible size.

$\mathrm{CO}_{2}$, as their NPP is not balanced by litterfall. Conversely, populated areas emit $\mathrm{CO}_{2}$ to the atmosphere by consuming food and feedstuff. This $\mathrm{CO}_{2}$ flux is a component of heterotrophic respiration, as it takes place away from the ecosystem. In between NPP and respiration, crop products are processed and transported. For instance, sugar crops are processed in the vicinity where they are harvested [Bourzutschky, 2004] but sugar is transported by trade and thus used further away. During the processing cascade specific to each crop, waste is generated, causing $\mathrm{CO}_{2}$ losses to the atmosphere. Since it was not possible to track the fate of carbon throughout the life cycle of crop products at the global scale, we developed an accounting model where we determined separately the distribution of $\mathrm{CO}_{2}$ sinks in croplands and the sources in populated regions. Input data are crop trade and harvest statistics from the Food and Agriculture Organization Agricultural Database (FAO-AD, 2004, available at http:// faostat.fao.org) (hereinafter referred to as FAO-AD database). We assumed that the first waste generated by processing the harvested biomass into one of the raw crop products defined by the FAO is decomposed into $\mathrm{CO}_{2}$ at the harvest location. Further crop products processing and transportation is quite efficient and so cause negligible losses of $\mathrm{CO}_{2}$, so that carbon sinks counted from raw products balance global carbon sources from transformed products. Further, we assumed that carbon from human or animal waste is decomposed into $\mathrm{CO}_{2}$ within less than a year. Given the low carbon conversion from feed to animal products, we assumed that all the feedstuff supplied to domestic animals was degraded and respired in situ. Finally, we neglected the storage of crop products which remains a negligible fraction of the harvest [Intergovernmental Panel on Climate Change, 2005], and the storage or trade of carbon carried into animals and animal products, which is very small compared to the food and feed carbon fluxes. In summary, the agro-carbon $\mathrm{CO}_{2}$ sinks are annually and globally compensated by $\mathrm{CO}_{2}$ sources, but the two fluxes have different spatial patterns. We calculated these patterns in sections $2-5$, and projected them into the distribution of atmospheric $\mathrm{CO}_{2}$ in section 6 using a global atmospheric transport model. Uncertainties were estimated in section 7.

\section{Material and Methods}

[5] First, we calculated the distribution of the $\mathrm{CO}_{2}$ sinks pertaining to crop harvest. The primary data are crop biomass production (harvest) statistics for 19 major crop categories and 208 countries (FAO-AD database). The biomass is converted into dry matter and then into carbon using crop specific factors [Goudriaan et al., 2001] (see auxiliary material ${ }^{1}$ ). The spatial patterns of carbon sinks in croplands are computed for each crop category, and projected on a crop specific fractional land cover map at $1^{\circ}$ [Leff et al., 2004]. Multiple crop rotation practice is not included. Within a large agricultural country, a crop variety

\footnotetext{
${ }^{1}$ Auxiliary material data sets are available at ftp://ftp.agu.org/apend/gb/ 2006gb002741. Other auxiliary material files are in the HTML.
} 
Table 1a. Top-10 Countries for Crop Carbon Harvest ${ }^{\mathrm{a}}$

\begin{tabular}{lccc}
\hline \multicolumn{1}{c}{ Country } & Production & Food Production & Feed Production \\
\hline China & 232.12 & 174.08 & 58.05 \\
United States & 188.06 & 93.79 & 94.27 \\
India & 141.16 & 128.96 & 12.20 \\
Brazil & 68.61 & 45.54 & 23.07 \\
Indonesia & 51.60 & 49.47 & 2.13 \\
France & 34.50 & 24.39 & 10.11 \\
Nigeria & 30.35 & 28.16 & 2.19 \\
Argentina & 29.52 & 14.14 & 15.37 \\
Malaysia & 26.13 & 24.64 & 1.49 \\
Canada & 25.06 & 12.56 & 12.49 \\
Globe & 1285.09 & 912.97 & 372.12 \\
Top10/Globe & 0.64 & 0.65 & 0.62 \\
\hline
\end{tabular}

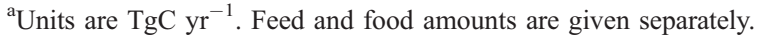

is often restricted to a specific region (e.g., the corn and wheat belts in North America). Therefore, in a large country it is important to use crop-specific fractional cover maps rather than a generic cropland map [Ramankutty and Foley, 1998] to project the geographic patterns of the sinks. Not doing so would result in smoother, less realistic patterns. We keep track at this stage of the fraction of harvest that will be exported and of the remaining fraction used domestically. The equations used to distribute the FAO-AD data into sinks maps are given in the auxiliary material.

[6] Second, we calculated the distribution of the respiratory $\mathrm{CO}_{2}$ sources caused by animal feedstuff and human food consumption. We divided the available carbon for consumption between food and feedstuff. For animal consumption, we assumed that only housed animals were given feedstuff from trade circuits, whereas grazing livestock relied on local forage and grass and were locally neutral for atmospheric $\mathrm{CO}_{2}$. From the feedstuff products inventoried in the FAO-AD database, we selected 21 major ones, including cakes of cereals and oilseeds, brans, pulses and grains composing the diet of farmed pigs and poultry and the concentrates in the diet of farmed cattle [Kuratorium fur Technic und Bauwessen in der Landwitschaft, 2000]. The supply of these feedstuffs was distributed successively to poultry, pigs and farmed cattle according to their specific nutritional demands using a simple feed model, with some country-dependent adjustments for farming intensity. In this model, described in more detail in the supplementary material, the poultry is fed first, according to national average management intensity, then pigs, and finally cattle. Poultry receives maize, and other cereals and a small share of the oilseed cakes/meals. Pigs receive maize, other cereals, oilseed cakes/meals, brans, pulses, and eventually oilseeds in case the demand is not covered by oilseed cakes/meals. Housed cattle receive the remaining maize, other cereals, oilseed cakes/meals, oilseeds and brans. Forage grass products entering into their diet are not considered here since their carbon is cycled locally. The contribution of the major feeds as a percentage of cattle diets agreed well with expected patterns of management intensities. We assumed that in developed countries, $100 \%$ of poultry, pigs and housed cattle received feedstuff to complete their diet, whereas this fraction was decreased to $20 \%$ in developing countries (see supplementary material). Once feedstuff quantities were distributed between poultry, pigs and cattle, we distributed the remaining $\mathrm{CO}_{2}$ sources using animals density maps [Lerner et al., 1988] at $1^{\circ}$ by $1^{\circ}$ resolution. Finally, for human food consumption, we established a list of 23 food products and estimated in each country the consumption of imported food. We then distributed the total amount of food products imported and produced domestically using human population densities at $1^{\circ}$ by $1^{\circ}[\mathrm{Li}$, 1996] (see auxiliary material).

\section{Results for Country Totals \\ 3.1. Production}

[7] The major producers are listed in Table 1a. Globally, the annual harvest amounts to $1285 \mathrm{TgC} / \mathrm{yr}$, roughly one third of the Net Primary Productivity of croplands [Goudriaan et al., 2001]. This quantity is equivalent to $\approx 15 \%$ of the fossil fuel emissions. The top- 10 producers are countries with a large population (e.g., China, India, Indonesia) or with an agricultural sector largely oriented to export (e.g., USA, Argentina, Canada). For instance, exported production on a yearly basis for Argentina is $70 \%$, for France and Canada $50 \%$ and for the USA, $30 \%$. The top- 10 producers altogether represent $64 \%$ of the global production. In populated Asian countries, the production is mostly food, whereas in non-Asian extratropical countries, the production distributes more evenly between food and feed products (Table 1a).

\subsection{Trade}

[8] The top-10 exporters of agricultural carbon are listed in Table $1 \mathrm{~b}$. These countries are generally temperate countries with favorable pedoclimatic conditions, intensive agriculture, subsidies, or vast areas of arable lands. They generate $78 \%$ of the carbon of crop products entering international trade circuits. The top-10 importers are countries with high population densities (including farmed animals) or with a rather dry climate (Table 1c). In Spain, Italy, and Mexico the imports of feedstuff are a larger carbon flux than the imports of food. In some countries, the imported flux may exceed the domestic production. In China however, the imported carbon flux remains very small compared to the huge domestic production $(232 \mathrm{TgC} / \mathrm{yr})$. Germany appears on both the top-10 exporters and top-10 importers lists, because it exports food products (grains) and

Table 1b. Top-10 Countries for Crop Carbon Harvest Export ${ }^{\mathrm{a}}$

\begin{tabular}{lccc}
\hline \multicolumn{1}{c}{ Country } & Total Export & Feed Export & Food Export \\
\hline United States & 47.56 & 12.69 & 34.87 \\
Argentina & 19.98 & 11.69 & 8.29 \\
France & 14.09 & 0.79 & 13.30 \\
Canada & 12.47 & 2.25 & 10.22 \\
Brazil & 10.15 & 8.80 & 1.35 \\
Australia & 9.25 & 0.01 & 9.24 \\
Thailand & 7.17 & 0.00 & 7.17 \\
Germany & 5.76 & 1.66 & 4.11 \\
Malaysia & 4.63 & 0.66 & 3.97 \\
China & 4.25 & 0.04 & 4.21 \\
Globe & 174.02 & 46.43 & 127.59 \\
Top10/Globe & 0.78 & 0.83 & 0.76 \\
\hline
\end{tabular}

${ }^{\mathrm{a}}$ Units are $\mathrm{TgC} \mathrm{yr}^{-1}$. Feed and food amounts are given separately. 
Table 1c. Top-10 Countries for Crop Carbon Import ${ }^{\mathrm{a}}$

\begin{tabular}{lccc}
\hline \multicolumn{1}{c}{ Country } & Total Import & Feed Import & Food Import \\
\hline Japan & 15.04 & 3.74 & 11.30 \\
China & 11.58 & 4.12 & 7.46 \\
Netherlands & 8.14 & 3.30 & 4.84 \\
Mexico & 7.16 & 1.04 & 6.12 \\
Korean Republic & 7.05 & 1.45 & 5.60 \\
Spain & 6.90 & 3.04 & 3.85 \\
Italy & 5.67 & 1.46 & 4.21 \\
Germany & 5.63 & 4.01 & 1.62 \\
Belgium-Luxembourg & 5.61 & 2.00 & 3.61 \\
Brazil & 5.01 & 0.25 & 4.76 \\
Globe & 163.19 & 41.38 & 121.80 \\
Top10/Globe & 0.48 & 0.59 & 0.44 \\
\hline
\end{tabular}

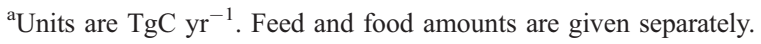

imports animal feedstuff. Finally, one can remark that the top-10 importers only comprise $50 \%$ of all imports of agrocarbon, indicating that the $\mathrm{CO}_{2}$ sources due to imported agro-carbon are distributed more evenly over the globe than the $\mathrm{CO}_{2}$ sinks in croplands.

\section{Result for Crop Totals}

\subsection{Production}

[9] The global harvest flux of carbon is broken down into different products in Table 2a. $60 \%$ of this flux results from cereals products, chiefly maize $(250 \mathrm{TgC} / \mathrm{yr})$, wheat (240 $\mathrm{TgC} / \mathrm{yr})$ and rice $(245 \mathrm{TgC} / \mathrm{yr})$. The second largest contribution to carbon fluxes after cereals is sugar cane (105 TgC/yr). Third are oilseeds (soybeans, oilpalm fruits) and fourth are roots and tubers (potato is the dominant species). Because of their high water content, roots and tubers represent a large mass of biomass, but a small mass of carbon. The same is true for fruit and vegetables, representing less than $5 \%$ of the global harvest of carbon. Further, only ten crop varieties among the 19 considered encompass $90 \%$ of the global amount of carbon harvested. In total, about $70 \%$ of the carbon is harvested for human nutrition while the remaining is used for housed animals. The feed to food ratio depends on each crop type. Maize and soybeans are used by animals, whereas wheat and rice are consumed by humans.

\subsection{Trade}

[10] The global trade flux of carbon $(174 \mathrm{TgC} / \mathrm{yr})$ is broken down into different products in Table $2 \mathrm{~b}$. The

Table 2a. Top-10 Crop Varieties for Agro-Carbon Harvest ${ }^{\mathrm{a}}$

\begin{tabular}{lccc}
\hline Crop Category & Production & Feed Production & Food Production \\
\hline Maize & 250.56 & 163.16 & 87.40 \\
Rice & 244.50 & 13.57 & 230.93 \\
Wheat & 240.38 & 48.62 & 191.76 \\
Sugarcane & 105.85 & 0.00 & 105.85 \\
Cassava & 66.99 & 0.00 & 66.99 \\
Soy & 64.15 & 42.71 & 21.45 \\
Oilpalm & 56.01 & 1.71 & 54.30 \\
Barley & 55.73 & 42.27 & 13.46 \\
Potato & 32.88 & 0.00 & 32.88 \\
Sorghum & 30.60 & 16.82 & 13.78 \\
Globe & 1285.09 & 372.12 & 912.97 \\
Top10/Globe & 0.89 & 0.88 & 0.90 \\
\hline
\end{tabular}

${ }^{\mathrm{a}}$ Units are $\mathrm{TgC} \mathrm{yr}^{-1}$. Feed and food amounts are given separately.
Table 2b. Top-10 Crop Varieties for Agro-Carbon Export ${ }^{\mathrm{a}}$

\begin{tabular}{lccc}
\hline Crop Category & Total Export & Feed Export & Food Export \\
\hline Wheat & 50.24 & 0.00 & 50.29 \\
Soy & 39.08 & 33.14 & 7.20 \\
Maize & 30.24 & 4.96 & 25.30 \\
Rice & 12.13 & 0.00 & 12.13 \\
Rape & 7.80 & 4.01 & 3.80 \\
Barley & 7.11 & 0.00 & 7.11 \\
Oilpalm & 6.61 & 1.22 & 5.38 \\
Cassava & 5.26 & 0.00 & 5.31 \\
Cotton & 3.94 & 0.22 & 4.09 \\
Sunflower & 3.54 & 3.51 & 0.04 \\
Globe & 174.02 & 47.88 & 145.35 \\
Top10/Globe & 0.95 & 0.98 & 0.83 \\
\hline
\end{tabular}

${ }^{\mathrm{a}}$ Units are $\mathrm{TgC} \mathrm{yr}^{-1}$. Feed and food amounts are given separately.

imported flux does not exactly balance the exported flux, partly owing to the (small) stocks formed each year, and partly because of gaps in the statistics. However, the net imbalance is very small $(11 \mathrm{TgC} / \mathrm{yr}$, i.e., less than $1 \%$ of the production). The relative importance of crop varieties in the trade carbon flux differs from the one in the harvest flux. Maize and wheat dominate (46\%) the trade fluxes. Oilseeds (soybeans, rapeseeds, oil-palm, sunflower seeds and associated products) are the second next category. Oilseeds represent a large fraction (31\%) of the trade of agro-carbon because of their high carbon to biomass ratio. In contrast, rice makes only a small contribution of the global trade, because it is consumed domestically. The top-10 traded products listed in Tables $2 \mathrm{~b}$ and $2 \mathrm{c}$ comprise $95 \%$ of the global trade. All of the wheat in trade circuits is used for human nutrition, as is $84 \%$ of the maize exported. In contrast $82 \%$ of the carbon flux of soybean or sunflower seeds trade is used for animal feed.

\section{Mapping the $\mathrm{CO}_{2}$ Fluxes Caused by Agricultural Carbon Displacement}

\subsection{Global Patterns for Wheat and Soybean}

[11] Figure 2 shows the $1^{\circ} \times 1^{\circ}$ spatial distribution of the components $\mathrm{CO}_{2}$ fluxes for wheat. The distribution of sinks where wheat is harvested (Figures $2 \mathrm{a}$ and $2 \mathrm{~b}$ ) shows large regional uptake values over western Europe, the North American midwest, South American temperate plains, and southeastern Australia. In these regions, wheat is primarily cultivated for export, unlike in Asia where it is used

Table 2c. Top-10 Crop Varieties for Agro-Carbon Import ${ }^{\mathrm{a}}$

\begin{tabular}{lccc}
\hline Crop Category & Total Import & Feed Import & Food Import \\
\hline Wheat & 47.18 & 0.00 & 47.18 \\
Soy & 38.29 & 31.98 & 6.31 \\
Maize & 28.49 & 1.97 & 26.52 \\
Rice & 10.03 & 0.15 & 9.88 \\
Rape & 6.84 & 4.55 & 2.29 \\
Barley & 6.72 & 0.00 & 6.72 \\
Oilpalm & 6.01 & 0.76 & 5.25 \\
Cassava & 5.14 & 0.00 & 5.14 \\
Cotton & 4.19 & 0.30 & 3.89 \\
Sorghum & 2.72 & 0.00 & 2.72 \\
Globe & 163.19 & 41.79 & 136.03 \\
Top10/Globe & 0.95 & 0.95 & 0.85 \\
\hline
\end{tabular}

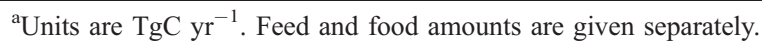




\section{Components of agro-carbon displacement for wheat}
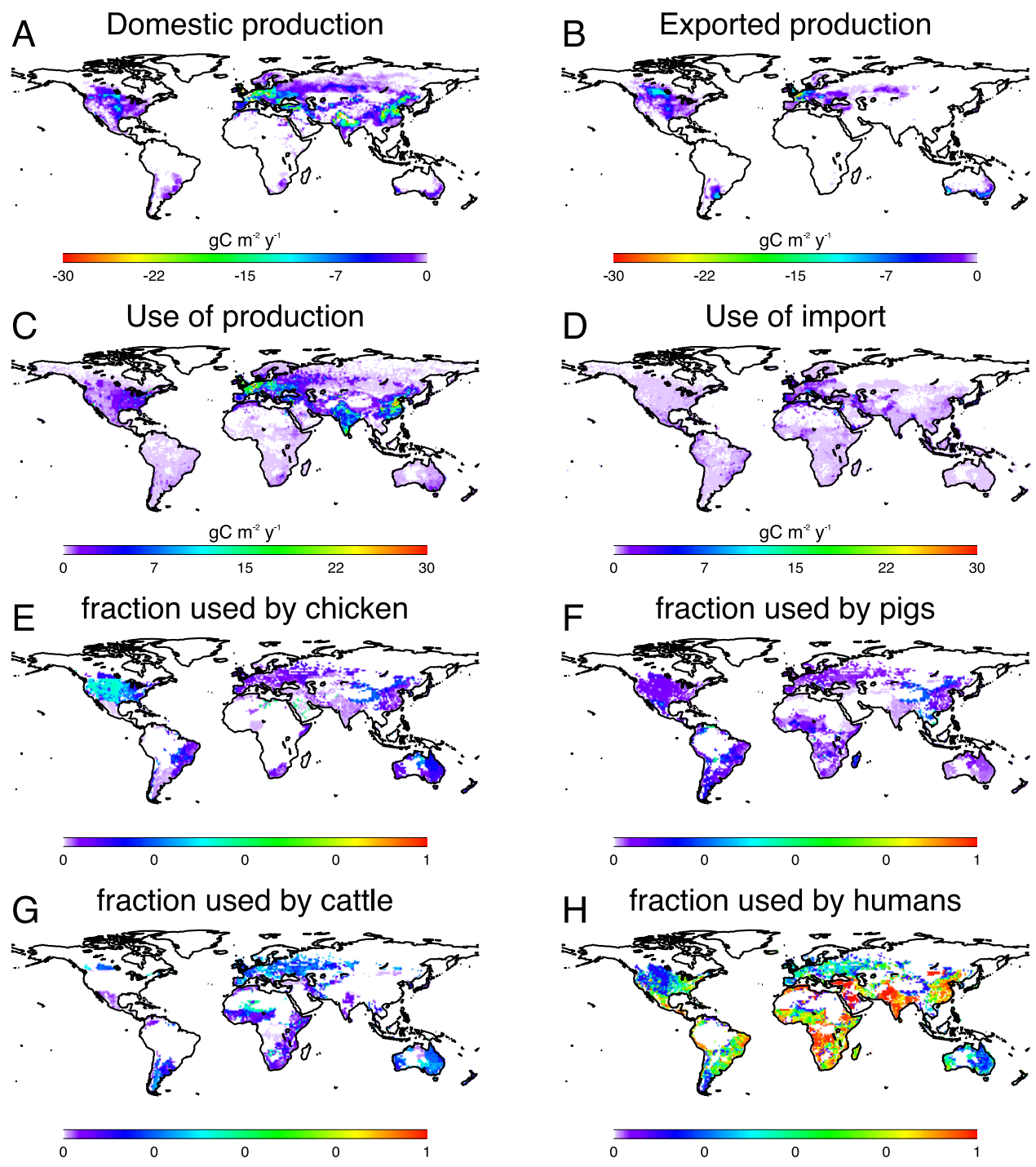

Figure 2. Distribution of $\mathrm{CO}_{2}$ fluxes associated with wheat products. Sinks from the atmosphere are negative and sources are positive. (a) Total harvest sink, (b) fraction of this sink which is exported via international trade circuits, (c) source caused by human and housed animal consumption, (d) fraction of that source coming from imported products, and $(\mathrm{e}-\mathrm{h})$ fraction of the total $\mathrm{CO}_{2}$ emissions from feedstuff consumed by poultry, pigs, housed cattle, and humans, respectively.

domestically. The $\mathrm{CO}_{2}$ sources due to consumption of wheat products (Figures 2c and 2d) show maxima over urbanized regions, around the Mediterranean basin, and in Africa and tropical Asia. The $\mathrm{CO}_{2}$ sinks in the midlatitude regions are compensated by $\mathrm{CO}_{2}$ sources in tropical regions. The fraction of wheat consumption by humans vs. animals (Figures $2 \mathrm{e}-2 \mathrm{~h}$ ) shows a predominant use by humans, although in some developed countries, up to $40 \%$ of the wheat can be used as a feedstuff (mostly for poultry).

[12] Figure 3 shows the patterns of $\mathrm{CO}_{2}$ fluxes for soybean. Comparing Figure 3 with Figure 2 shows that soybean $\mathrm{CO}_{2}$ sinks occur all over the globe, whereas the wheat sinks were restricted to the midlatitude regions. The soybean $\mathrm{CO}_{2}$ sinks are particularly intense in the United States, Brazil, and Argentina, whereas in contrast, the wheat sinks were much more diffuse. Generally, the export of soybean carbon creates a larger uptake than the domestic production flux (Figures 3a and 3b), except over China. The source of $\mathrm{CO}_{2}$ from feedstuff containing soybeans is larger than the one from food products. Treating the feeding of farmed animals explicitly in addition to the human consumption (see section 3) produces a smoother $\mathrm{CO}_{2}$ source field (Figures $3 \mathrm{e}-3 \mathrm{~g}$ ) than assuming the source to be explained entirely by human consumption because animal 


\section{Components of agro-carbon displacement for soybeans}
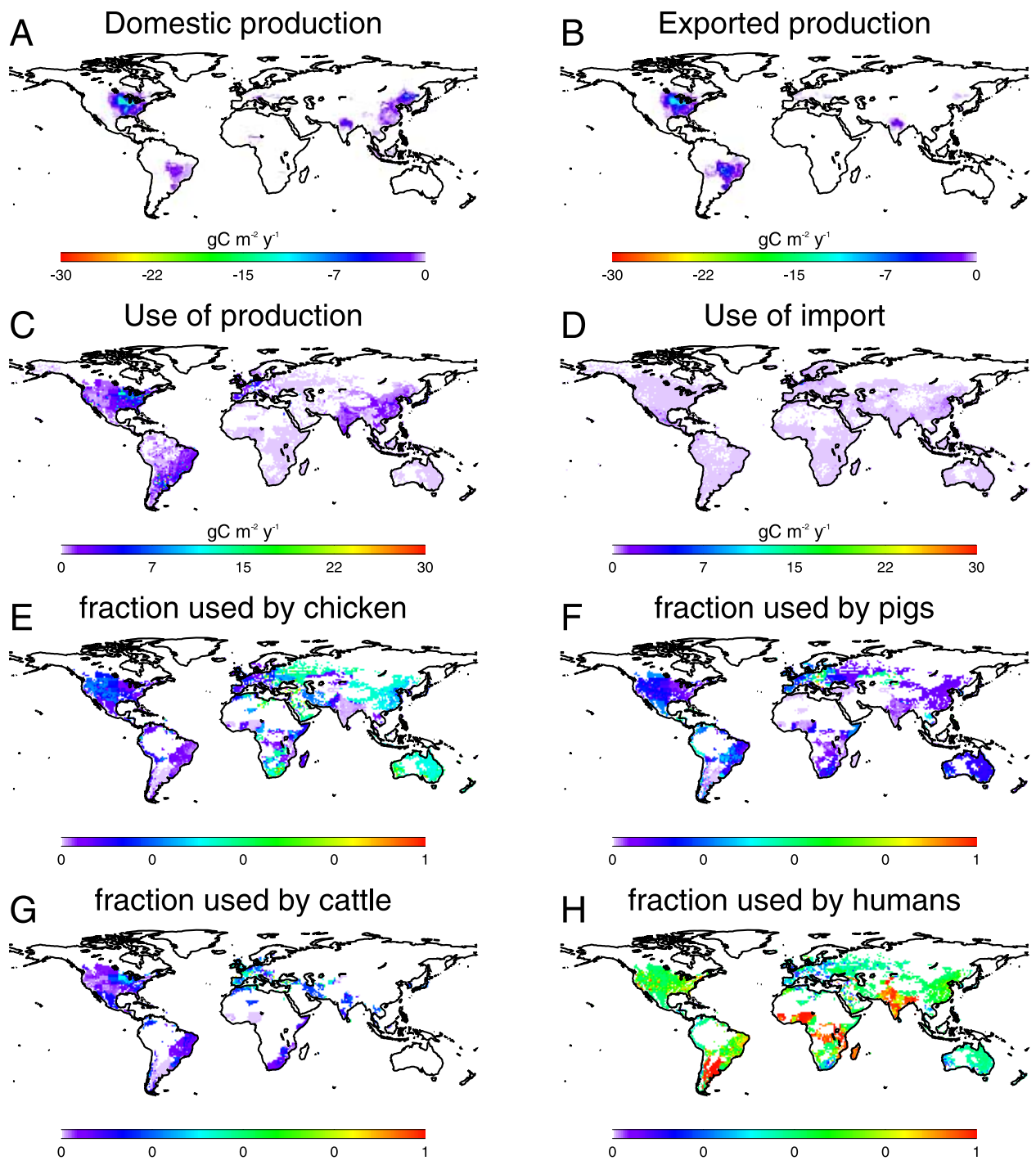

Figure 3. Same as Figure 2 but for soybeans.

population densities are more homogeneous than those of humans [Lerner et al., 1988]. Note that the type of animals and the ratio of human to animal population densities varies from one country to the next, and within each same country, so that the contribution of each region to the $\mathrm{CO}_{2}$ emissions from soybeans use is far from geographically uniform (Figure 2h).

\subsection{Global Patterns for All Crops}

[13] Figure 4 shows the distribution of the $\mathrm{CO}_{2}$ flux caused by agricultural carbon harvest and use. This flux is the sum of the $\mathrm{CO}_{2}$ fluxes for the 19 different crop categories considered here. Some regional contrasts appear, with the largest sources (max. $615 \mathrm{gC} \mathrm{m}^{-2} \mathrm{yr}^{-1}$ in China) in highly populated regions, especially in mega-cities. The $\mathrm{CO}_{2}$ flux distribution is highly skewed, with point-wise sources (cities) and more diffuse sinks over croplands. The largest spatially coherent sinks of atmospheric $\mathrm{CO}_{2}$ are the North American midwest (cereals), eastern Europe (cereals, potatoes), northern China (wheat and cereals) and the Ganges and Indus plains in northern India (wheat, rice). Significant sinks are also found in Brazil (soybean), Argentina (cereals), and southern Australia (wheat). The $\mathrm{CO}_{2}$ flux density for sinks is on the order of $50 \mathrm{gC} \mathrm{m}^{-2} \mathrm{yr}^{-1}$.

[14] A few source-sink dipoles appear at the subcontinental level (Figure 4). The most striking example is a $\mathrm{CO}_{2}$ source in populated regions of northern China $\left(\approx 40^{\circ} \mathrm{N}\right)$, bracketed by sinks both to the south and to the north. Another large dipole exists over North America between the midwest sink of $\mathrm{CO}_{2}$ and sources on the east coast. In India, there is a cropland sink in the north compensated by a source in the south. In western Europe however, the patterns of the 

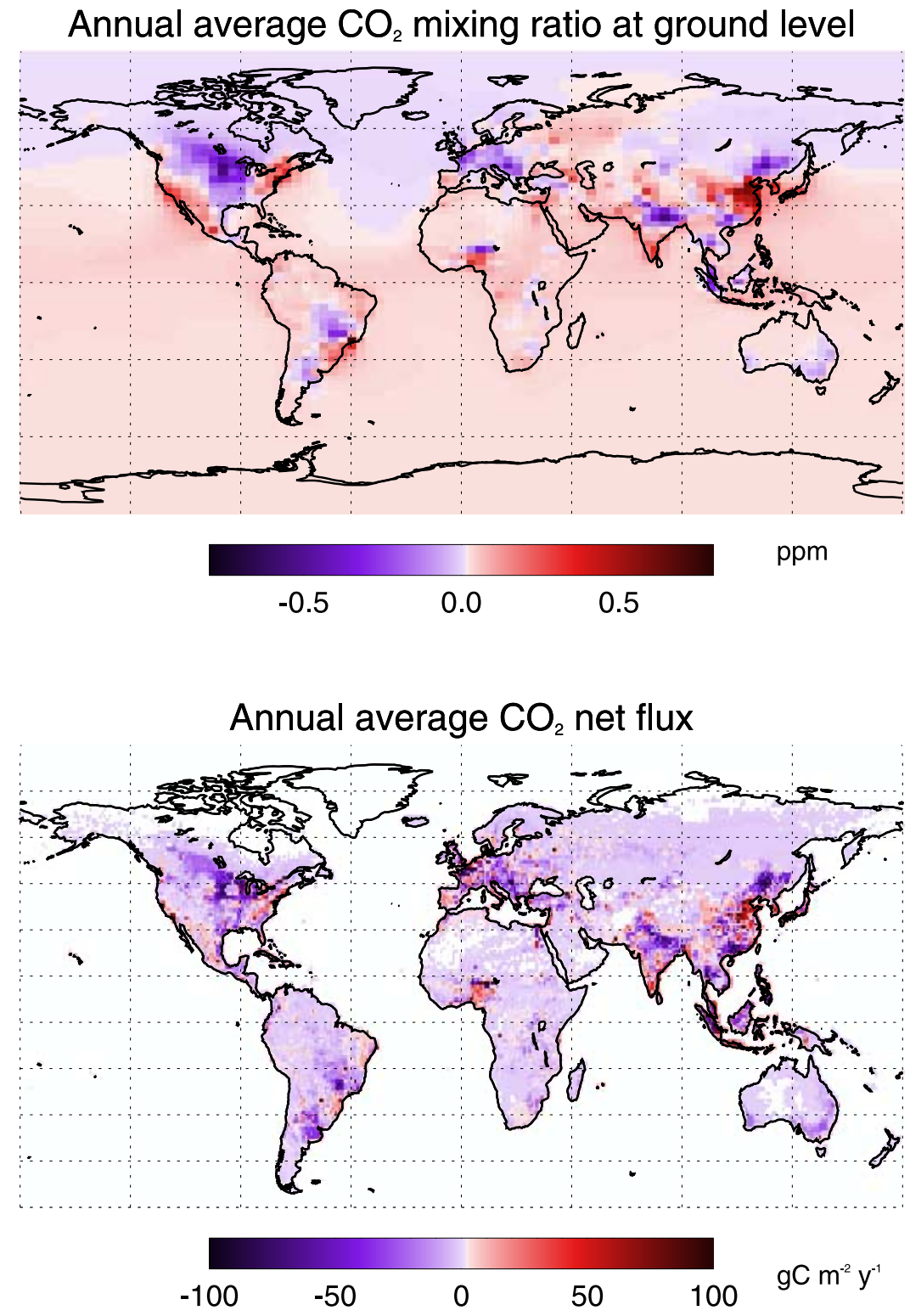

Figure 4. (top) Map of annual mean $\mathrm{CO}_{2}$ mixing ratio at the ground level simulated with the LMDZ global transport model (value at South Pole has been taken as an arbitrary reference). (bottom) Map of $\mathrm{CO}_{2}$ fluxes associated with agro-carbon displacement $\left(\mathrm{CO}_{2}\right.$ sources to the atmosphere are positive and sinks are negative).

$\mathrm{CO}_{2}$ fluxes caused by agro-carbon are complex, with urban source areas and rural sink areas being closer to each other.

[15] The global mean flux of $\mathrm{CO}_{2}$ induced by agro-carbon displacement is zero. Regionally however, the annual magnitude of that flux is not negligible compared to continental or regional-scale carbon budgets [Janssens et al., 2005]. With annual mean $\mathrm{CO}_{2}$ uptake rates of $50 \mathrm{gC} \mathrm{m}^{-2} \mathrm{yr}^{-1}$ (see Figure 4), croplands are local carbon sinks of comparable magnitude than forests [Baldocchi et al., 2001]. The $\mathrm{CO}_{2}$ sources caused by feed and food consumption (total source $1.3 \mathrm{GtC} / \mathrm{yr}$ ) have a spatial pattern similar to the one used for fossil fuel emissions (6.4 GtC/yr during the 1990s [Andres et al., 1999]). Thus, seen from the atmosphere, the $\mathrm{CO}_{2}$ emissions from densely populated regions are up to $20 \%$ higher than when counting fossil fuel emissions alone. This is illustrated in Table 3 for four large Chinese cities, where the ratio of $\mathrm{CO}_{2}$ losses from food to fossil fuel emissions reaches values of $30 \%$ for the Beijing urban area and $20 \%$ for Chongquing. In less industrialized but highly populated regions, the ratio of agro-carbon $\mathrm{CO}_{2}$ losses to fossil fuel emission is sometimes greater than one.

\subsection{Latitudinal Patterns}

[16] Figure 5 shows $\mathrm{CO}_{2}$ flux averaged by latitude bands due to the trade of crop carbon. One can see two sink zones in the Northern Hemisphere. The main one (170 TgC/yr 
Table 3. Comparison Between Local Food $\mathrm{CO}_{2}$ Losses and Fossil Fuel $\mathrm{CO}_{2}$ Emissions for Four Large Chinese Cities ${ }^{\mathrm{a}}$

\begin{tabular}{lccccc}
\hline \multicolumn{1}{c}{ City } & Area, $\mathrm{km}^{2}$ & Population, Millions & Fossil $\mathrm{CO}_{2}$ Emissions, $\mathrm{gC} \mathrm{m}^{-2} \mathrm{yr}^{-1}$ & Food CO $_{2}$ Emissions, $\mathrm{gC} \mathrm{m}^{-2} \mathrm{yr}^{-1}$ & Food to Fossil Ratio \\
\hline Beijing & 16,800 & 13.8 & 492.9 & 147.8 & 0.30 \\
Shanghai & 6200 & 16.74 & 1620.0 & 216 & 0.13 \\
Chongquing & 82,000 & 30.9 & 226.1 & 45.6 & 0.20 \\
Hong-Kong & 1103 & 6.94 & 3775.2 & 26 & 0.01 \\
\hline
\end{tabular}

${ }^{\mathrm{a}}$ The fossil $\mathrm{CO}_{2}$ emissions were estimated from urban area, population data, and country specific per-capita emission ratios available from http:// cdiac.esd.ornl.gov/ftp/trends/emissions/prc.dat.

over $37^{\circ} \mathrm{N}-60^{\circ} \mathrm{N}$ ) is placed at northern midlatitudes. It corresponds to maize, wheat and barley production in Europe and North America. A second, but smaller, sink zone $\left(50 \mathrm{TgC} / \mathrm{yr}\right.$ over $20^{\circ} \mathrm{N}-30^{\circ} \mathrm{N}$ corresponds chiefly to rice cultivation in the northern tropics, with a small additional contribution from sugarcane. Minor sink regions are found at around $5^{\circ} \mathrm{N}$ (cassava), and at around $20^{\circ} \mathrm{S}$ (sugarcane and cereals in Brazil). The $\mathrm{CO}_{2}$ sources caused by the use of crop products are more uniformly distributed in latitude than the sinks. One can distinguish in the zonal mean a few peaks of $\mathrm{CO}_{2}$ emissions (e.g., Asian megacities). Note that the dipole formed by emissions in northern China and the uptake south of this region remains visible in the zonal average curve of Figure 5.

\section{Impact on Atmospheric $\mathrm{CO}_{2}$ Distribution}

[17] We computed the impact of the displacement of agrocarbon on the atmospheric $\mathrm{CO}_{2}$ concentration field. To do so, we used the 3D global atmospheric tracer transport model LMDZt [Hourdin and Armengaud, 1999] at a horizontal resolution of $3.75^{\circ}$ by $2.5^{\circ}$ with 19 vertical levels (see auxiliary material). We assigned the temporal pattern of the NPP model of Lafont et al. [2002] to the production of crop biomass. This NPP model is based on canopy light interception from the SPOT4-VEGETATION sensor NDVI data (April 1998 to March 1999) and uses a light use efficiency formulation. We assumed that the $\mathrm{CO}_{2}$ emissions from animals and humans are constant each month. The fact that the respiration of agricultural carbon is flat in time as opposed to soil respiration flattens the seasonal amplitude of the heterotrophic respiration curve, and hence increases the amplitude of NEP.

[18] The annual mean modeled $\mathrm{CO}_{2}$ concentration near the surface is shown in Figure 4. It reflects the distribution of sources and sinks (Figure 4), with concentration dipoles of $+0.5 /-0.5 \mathrm{ppm}$ over North America, China, India. Regional $\mathrm{CO}_{2}$ minima over agricultural regions are on the order of $-0.3 \mathrm{ppm}$ (Figure 4). The $\mathrm{CO}_{2}$ concentration gradients in latitude ( 0.1 to $0.2 \mathrm{ppm})$ are negligible compared to the interhemispheric difference of $4 \mathrm{ppm}$. The concentration gradients in longitude are comparable to those induced by other sources and sinks processes (e.g., Fan et al. [1998] inferred a big carbon sink in the US from a 0.4 ppm difference in mean $\mathrm{CO}_{2}$ between sites over the Atlantic and Pacific oceans). As the network of $\mathrm{CO}_{2}$ measurement stations will increase in density over continental areas, the effect of agro-carbon fluxes must be accounted for include for explaining $\mathrm{CO}_{2}$ gradients across these sites.

[19] Figure 5 shows the $\mathrm{CO}_{2}$ concentration as a function of latitude. The model was sampled at the stations of the
GLOBALVIEW surface network [GLOBALVIEW-CO, 2004]. The sites most influenced by agro-carbon displacement are LEF (Wisconsin), TAP (Korea), SCS (South China Sea Cruises), and HUN (Hungary). Some stations such as HUN (Hungary), ORL (Orleans), LEF (Wisconsin) located downwind of large cropland areas are $0.2-0.3 \mathrm{ppm}$ below the marine boundary layer reference curve (Figure 5). Conversely, the respiration of crop products causes a positive $\mathrm{CO}_{2}$ difference of up to $0.4 \mathrm{ppm}$ above the marine baseline at stations SCS-21 (South China Sea, $21^{\circ} \mathrm{N}$ ) and LJO (California), both located downwind of urban areas.

[20] Figure 6 shows the seasonal cycle of atmospheric $\mathrm{CO}_{2}$ pertaining to the trade of agro-carbon at four GLOBALVIEW stations influenced by this effect. The trade of carbon augments the amplitude of the $\mathrm{CO}_{2}$ seasonal cycle by a small amount (maximum effect of $0.5 \mathrm{ppm}$ on peak to peak at LEF in Wisconsin or at HUN). The seasonal cycle at other continental sites such as UUM (Mongolia), ORL (Orleans), and BSC (Black Sea) is augmented by $0.3 \mathrm{ppm}$. The seasonal cycle at background marine sites is augmented by only a small amount $(0.15 \mathrm{ppm}$ at Mauna Loa and $0.2 \mathrm{ppm}$ at Point Barrow). These data indicate that the carbon trade explains only a very small fraction (maximum $5 \%$ ) of the $\mathrm{CO}_{2}$ seasonal cycle amplitude at northern midlatitude stations. These data tentatively suggests that over the last 20 years, the dramatic increase in agricultural productivity could have contributed up to $10 \%$ to the observed positive trend in the seasonal amplitude of $\mathrm{CO}_{2}$ (+2 ppm at Mauna Loa [after, e.g., Randerson et al., 1997]).

\section{Uncertainties}

[21] First, biases in the statistical data sets create systematic errors in carbon fluxes. Olivier et al. [1994] reported that: "For agricultural production, often reasonably accurate international statistics are available". Here uncertainties in the agricultural statistics from the few largest producers and exporters (Tables 1a and 1b) will dominate global uncertainties. We cannot determine which inventories are correct, but a range of error can be estimated by using different statistical data sets. For the United States (where statistics are expected to be of high quality), we compared soybeans and cereals harvest between the FAO-AD and the USDA databases [U.S. Department of Agriculture, 2000]. Figure 7 compares the two data sets for nine consecutive years during 1990-1998. The systematic differences between FAO-AD and USDA can be analyzed by calculating the relative bias, defined as the mean difference over 19901998 divided by the average over that period. We obtain relative bias values of USDA versus FAO-AD data sets of $-0.2 \%$ for cereals (negligible) and $7 \%$ for soybeans. This 

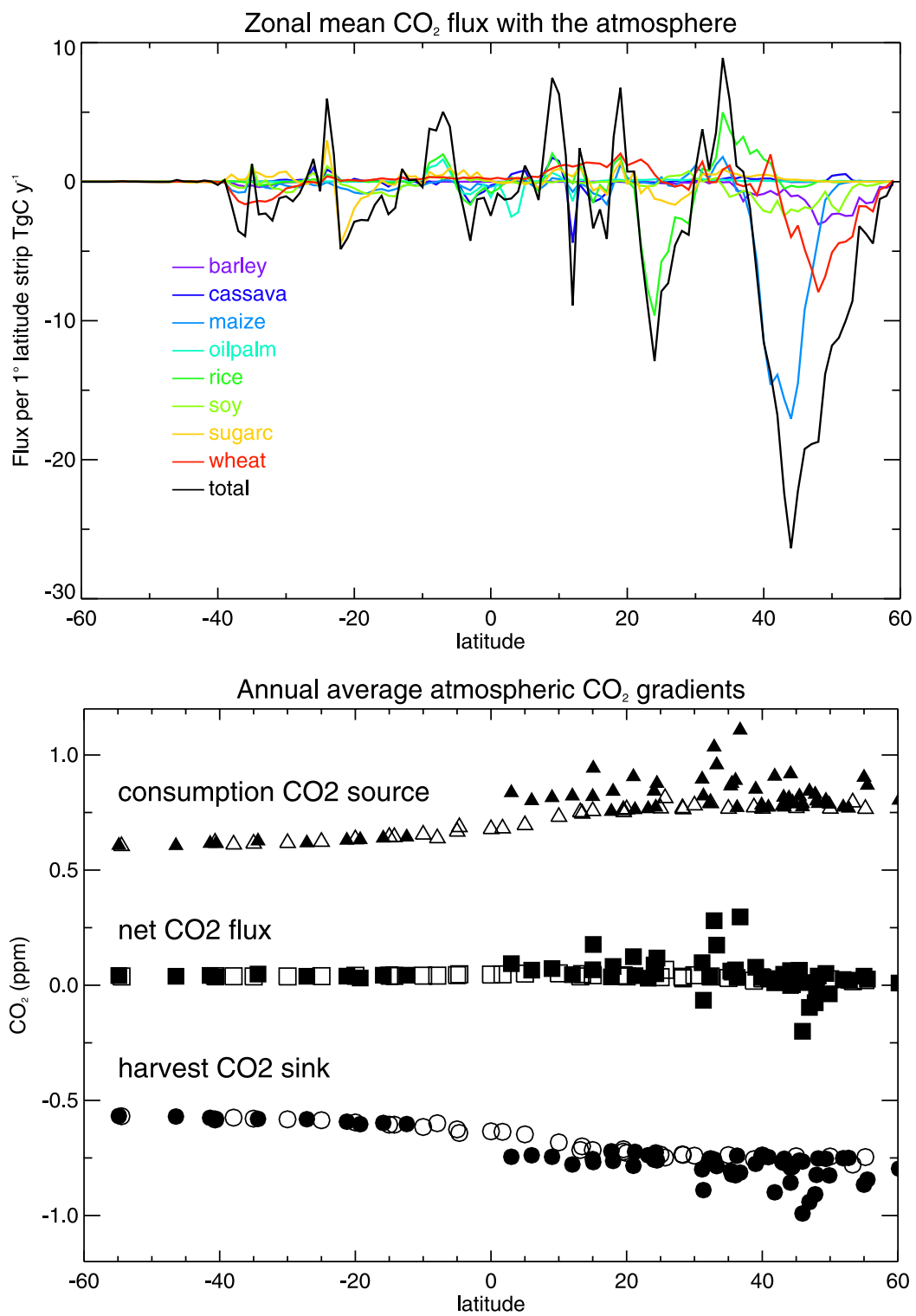

Figure 5. (top) Annual mean simulated $\mathrm{CO}_{2}$ concentration function of latitude at the GLOBALVIEW stations. The sink (harvest) and source (consumption) components are shown separately. In the middle is the $\mathrm{CO}_{2}$ signal corresponding to the net effect of crop-carbon trade. (bottom) Zonally $\mathrm{CO}_{2}$ fluxes. We only show the seven most important crop varieties which contribute to the zonal mean, out of the 19 analyzed in total.

bias is not constant from one year to the next, which results into a scatter around the 1:1 slope. We treated this scatter as a random error, although it could have a systematic origin. The Root Mean Squared Error (RMSE) between the USDA

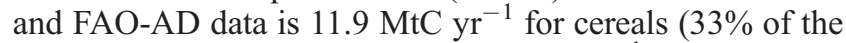

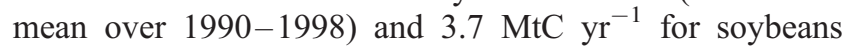
( $40 \%$ of the mean). This indicates that a large bias can originate from the use of a particular statistical data set during a single year, whereas these differences may become smaller when considering decadal average fluxes. Some differences result from different definitions or accounting practices; for example cereal stocks are explicitly included in USDA data but not in the FAO-AD.
[22] Secondly, an error is introduced by minor gaps and inconsistencies within the FAO-AD data set. For instance, exported fluxes exceed the harvest fluxes in BelgiumLuxemburg, Singapore, United Arab Emirates and the Netherlands, which reflects the fact that those countries report in their trade statistics products which cross their boundaries to be consumed elsewhere. Summing over all countries and all crop products, we estimate a global bias of $6 \mathrm{TgC} / \mathrm{yr}$ caused by inconsistencies in FAO-AD. This error is small, since it represents only $3.5 \%$ of the total export, but locally it could be more significant.

[23] Thirdly, there is uncertainty in the maps of human and animal population densities used to project country 

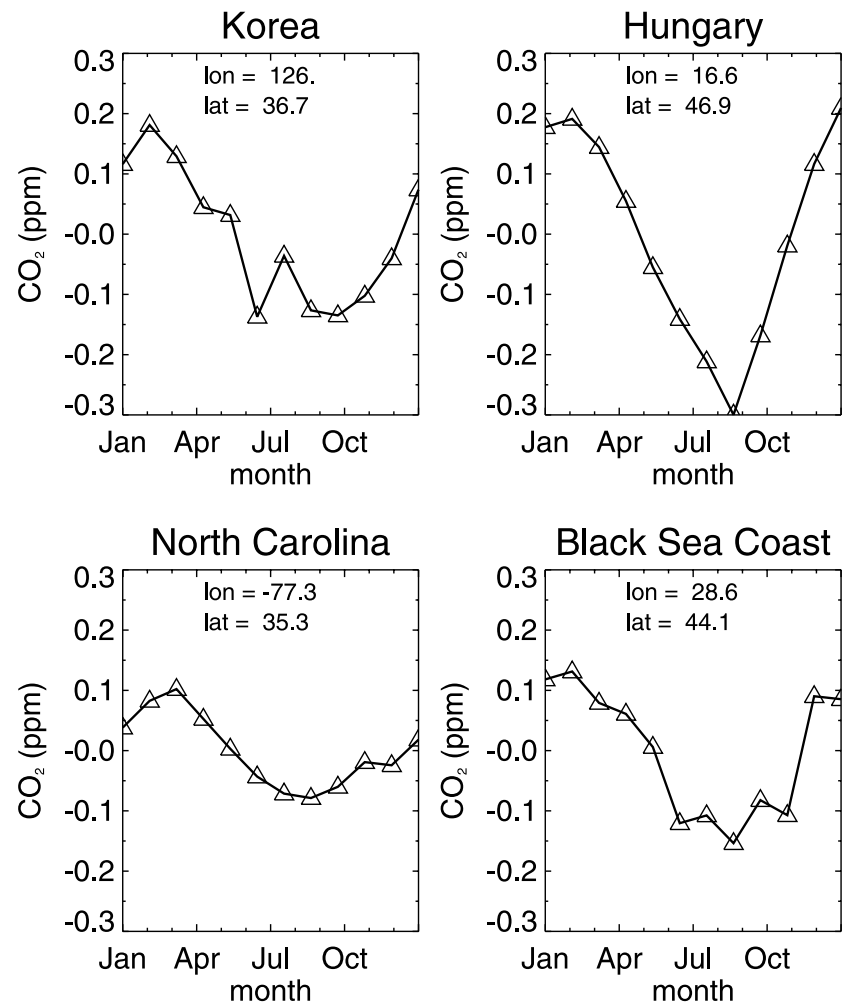

Figure 6. Seasonal cycle of $\mathrm{CO}_{2}$ caused by crop carbon trade at four stations in Korea (TAP), Hungary (HUN), North Carolina (ITN), and the Black Sea (BSC).

totals over a global grid. The farmed animals population densities were fixed using 1984 data [Lerner et al., 1988], and regional trends after 1984 were ignored. The effects of an uncertain thematic activity map could, in future studies, be estimated by comparing different versions of that map, constructed for instance with different methodologies to fill missing sections. In documentation of the EDGAR 2.0 emission database (http://www.rivm.nl/geia/documentation/) an uncertainty level of $\pm 20 \%$, termed as "small" is estimated for animal population densities. We interpret this estimate as indicative of the uncertainty in the spatial patterns of the feed consumption $\mathrm{CO}_{2}$ flux.

[24] Further errors in $\mathrm{CO}_{2}$ fluxes are due to a simplified treatment of the cycle of agricultural carbon. We neglected waste production when the 19 raw crop product harvest statistics were transformed into the 41 processed foods and feed products. The associated error should be small, since the processing of grain (the largest trade carbon flux) before trade creates negligible waste. We neglected the carbon flux in waste displacement and storage (see Figure 1). This approximation is the worst for human wastes stored in landfills. The IPCC panel [Intergovernmental Panel on Climate Change, 2005] assumes first-order decay with a decay rate of 0.2 (equal to a half-life of 3 years). All other wastes (incinerated, wastewaters) have shorter residence times, so that in total, ignoring the waste carbon pool only causes a small error in the $\mathrm{CO}_{2}$ fluxes. We neglected the trade of meat products. According to FAO-AD and converted to carbon units (meat moisture $=65 \%, \mathrm{~N}$ in dry matter $=2.4 \%, \mathrm{C} / \mathrm{N}=5)$, the global meat trade is 1.6-2.6 $\mathrm{GgC} \mathrm{yr}^{-1}$ (the range is the difference between export and import). This estimate ignores other animal products (milk, eggs), but shows unambiguously that the carbon flux in animal products is negligible compared to carbon flux contained in vegetable products.

[25] Finally, there is an uncertainty in the feed model. An error comes from unknown regional discrepancies in farming intensities within countries. Because of this, our $\mathrm{CO}_{2}$ flux maps are probably too smooth. Possible errors in the feed allocation to different animal categories lead to relatively small errors in $\mathrm{CO}_{2}$ fluxes if the different animal population densities map correlate well with each other (this corresponds to a an error of a few percent from the tests we made). While the physiological nutritional demands by animal category are globally robust, the discrepancy between actual feed supply and physiological optimum feeding also introduces an error. However, in developed countries, where the share of feed is important, we can assume that the actual feeding is close to the physiological optimum. The large uncertainties in developing countries may end up being relatively minor overall because feedcarbon represents only a minor share of agro-carbon.

\section{Conclusion}

[26] The distribution of $\mathrm{CO}_{2}$ fluxes caused by harvest, trade and use of crop products was mapped. Globally, this flux is close to zero. Regionally, a total flux of $1285 \mathrm{TgC} / \mathrm{yr}$ is displaced, of which $174 \mathrm{TgC} / \mathrm{yr}(13 \%)$ is displaced by international trade. Croplands are net $\mathrm{CO}_{2}$ sinks in the annual mean, whereas cities and areas of intensive farming

\section{Comparison of different statistical data sets 1990-1998}

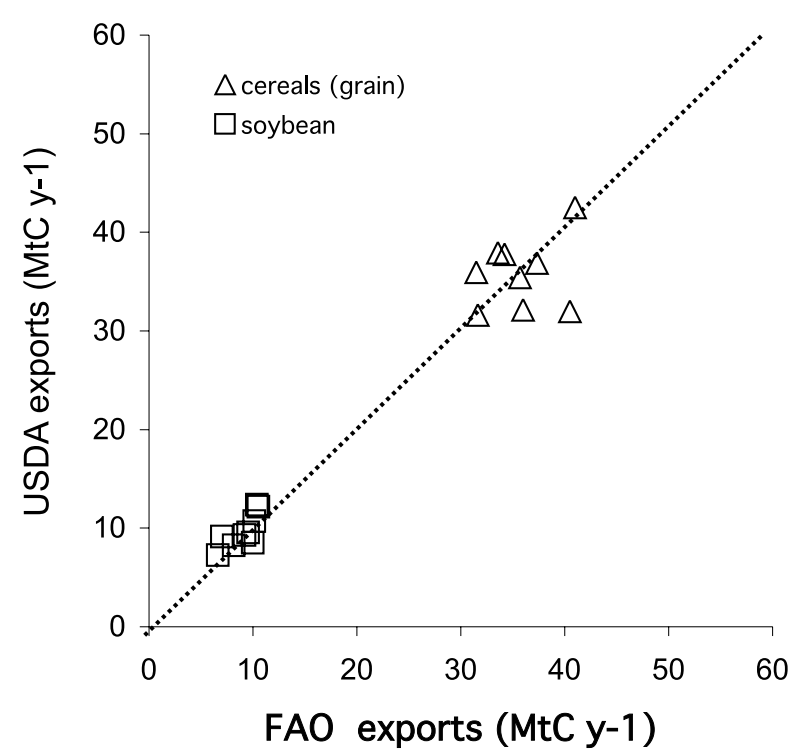

Figure 7. Comparison between the USDA and FAO-AD agricultural data sets of grain (maize + wheat) and soybeans harvest over 1990-1998. The same biomass-to-carbon conversion factors were applied to both agricultural data sets. 
are net $\mathrm{CO}_{2}$ sources. Regional dipoles of sources and sinks were accordingly found in North America and China. In Europe, however, regional contrasts between sinks and sources are not well differentiated at our working resolution of $1^{\circ}$. When prescribing these $\mathrm{CO}_{2}$ fluxes to an atmospheric transport model, we simulated small annual mean $\mathrm{CO}_{2}$ gradients in latitude $(<0.2 \mathrm{ppm})$, which correspond to a carbon flux of $200 \mathrm{TgC} / \mathrm{yr}$ displaced southward across $30^{\circ} \mathrm{N}$. We simulated gradients in longitude at northern midlatitudes of $0.3 \mathrm{ppm} /-0.3 \mathrm{ppm}$. Such longitudinal gradients are on the same order of magnitude as those observed between atmospheric stations (e.g., the difference between Atlantic and Pacific ocean sites), suggesting that $\mathrm{CO}_{2}$ fluxes from food and feedstuff trade are an important component of continental and regional-scale $\mathrm{CO}_{2}$ budgets. Assuming that the respiratory $\mathrm{CO}_{2}$ flux from food and feed consumption is flat in time, instead of peaking in summer if the same amount of carbon was allowed to decompose in ecosystems, we modeled that the displacement of crop carbon modified the amplitude of the $\mathrm{CO}_{2}$ seasonal cycle in the Northern Hemisphere by up to $0.5 \mathrm{ppm}$ at continental sites.

[27] Atmospheric inversions determine a set of surface fluxes in best agreement with observed atmospheric $\mathrm{CO}_{2}$ gradients, within the errors in the gradients. Inverting terrestrial fluxes is an ill-constrained problem, where uncertain and sparse data translate into large errors in fluxes [Gurney et al., 2002]. The $\mathrm{CO}_{2}$ gradients caused by agrocarbon displacement can thus erroneously be inverted into sinks and sources over the wrong regions. Forcing prior fluxes in inversions to follow the spatial patterns of NPP as for instance in the work by Gurney et al. [2002] or Rödenbeck et al. [2003] is further not compatible with the regional patterns of $\mathrm{CO}_{2}$ sources and sinks from crop product displacement. Further, even if regional $\mathrm{CO}_{2}$ fluxes calculated from inversions were unbiased, ignoring the existence of agro-carbon displacement would still lead to errors in attributing inversion results to processes. For instance, the fact that the $\mathrm{CO}_{2}$ source due to food consumption is spatially confounded with fossil $\mathrm{CO}_{2}$ emissions could be misinterpreted as a correction to fossil fuel emissions. Because the agricultural statistics are relatively accurate, the crop-products $\mathrm{CO}_{2}$ fluxes can easily be included explicitly as a basis function with an error $(10-20 \%)$ in regional inversions. Future improvements of this work could come from the derivation of higher-resolution maps for long-term regional carbon budgeting experiments, such as the CARBOEUROPE regional experiment (http://carboregional.mediasfrance. org/projet/index) and the NACP midcontinental regional experiment (http://www.nacarbon.org/nacp/documents/ NACP_MCI_SciPlan_8-06.pdf).

[28] Acknowledgments. We thank J. Tschirley at FAO for his kind help in providing the agricultural data sets and N. Ramankutti for making available their maps of crop types.

\section{References}

Andres, R. J., D. J. Fielding, G. Marland, T. Boden, N. Kumar, and A. T. Kearney (1999), Carbon dioxide emissions from fossil-fuel use, 17511950, Tellus, Ser. B, 51, 759-765.
Baldocchi, D., et al. (2001), FLUXNET: A new tool to study the temporal and spatial variability of ecosystem-scale carbon dioxide, water vapor, and energy flux densities, Bull. Am. Meteorol. Soc., 82, 2415-2434.

Bourzutschky, H. C. C. (2004), Aspects of cane sugar and cane sugar technology-Part 1 (in German), Zuckerindustrie, 129, 85-91.

Fan, S., M. Gloor, J. Mahlman, S. Pacala, J. Sarmiento, T. Takahashi, and P. Tans (1998), A large terrestrial carbon sink in North America implied by atmospheric and oceanic carbon dioxide data and models, Science, $282,442-446$.

Freibauer, A., M. D. A. Rounsevell, P. Smith, and A. Verhagen (2004), Carbon sequestration in the agricultural soils of Europe, Geoderma, 122, $1-23$

Gervois, S., N. de Noblet-Ducoudre, N. Viovy, P. Ciais, N. Brisson, B. Seguin, and A. Perrier (2004), Including croplands in a global biosphere model: Methodology and evaluation at specific sites, Earth Interact., 8(16), doi:1087-62(2004)8<1:ICIAGB>2.0.CO;2.

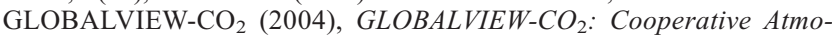
spheric Data Integration Project-Carbon Dioxide [CD-ROM], Clim. Monit. Diag. Lab., Natl. Oceanic and Atmos. Admin., Boulder, Colo. (Available on Internet via anonymous FTP to ftp.cmdl.noaa.gov, Path: $\mathrm{ccg} / \mathrm{co} 2 /$ GLOBALVIEW)

Goudriaan, J., J. J. R. Groot, and P. W. J. Uithol (2001), Productivity of agro-ecosystems, in Terrestrial Global Productivity, edited by J. Roy et al., pp. 189-210, Elsevier, New York.

Gurney, K. R., et al. (2002), Towards robust regional estimates of $\mathrm{CO}_{2}$ sources and sinks using atmospheric transport models, Nature, 415, $626-630$.

Houghton, R. A. (2003), Revised estimates of the annual net flux of carbon to the atmosphere from changes in land use and land management $1850-$ 2000, Tellus, Ser. B, 55, 378-390.

Hourdin, F., and A. Armengaud (1999), The use of finite-volume methods for atmospheric advection of trace species: 1 . Test of various formulations in a general circulation model, Mon. Weather Rev., 127, 822-837.

Imhoff, M. L., L. Bounoua, T. Ricketts, C. Loucks, R. Harriss, and W. T. Lawrence (2004), Global patterns in human consumption of net primary production, Nature, 429, 870-873.

Intergovernmental Panel on Climate Change (2005), Good Practice for Land-Use, Land-Use Change and Forestry, Inst. for Global Environ. Strategies (IGES), Kanagawa, Japan.

Janssens, I. A., et al. (2005), The carbon budget of terrestrial ecosystems at country-scale-A European case study, Biogeosciences, 2, 15-26.

Kucharik, C. J. (2003), Evaluation of a process-based agro-ecosystem model (Agro-IBIS) across the U.S. corn belt: Simulations of the interannual variability in maize yield, Earth Interact., 7(14), doi:10.1175/ 1087-3562(2003)007<0001:EOAPAM >2.0.CO;2.

Kuratorium fur Technic und Bauwessen in der Landwitschaft (2000), KTBL Pocket Book Agriculture 2000/01 (in German), 20th ed., Kuratorium fur Technic und Bauwessen in der Landwitschaft, Munster, Germany.

Lafont, S., K. Kergoat, G. Dedieu, A. Chevillard, E. Kjellström, U. Karstens, and O. Kolle (2002), Spatial and temporal variability of land $\mathrm{CO}_{2}$ fluxes estimated with remote sensing and analysis data over western Eurasia, Tellus, Ser. B, 54, 820-833.

Leff, B., N. Ramankutty, and J. Foley (2004), Geographic distribution of major crops across the world, Global Biogeochem. Cycles, 18, GB1009, doi:10.1029/2003GB002108.

Lerner, J., E. Matthews, and I. Fung (1988), Methane emission from animals: A global high-resolution database, Global Biogeochem. Cycles, 2, $139-156$.

Li, Y. F. (1996), Global Population Distribution Database: A report to the United Nations Environment Programme under UNEP Sub-Project FP/ 1205-95-12, report, U. N., New York. (Available at http://na.unep.net/ globalpop/1-degree/)

Morgan, D. (1980), Merchants of Grain, Penguin, New York.

Olivier, J. G. J., A. F. Bouwman, C. W. M. Van der Maas, and J. J. M. Berdowski (1994), Emission Database for Global Atmospheric Research (EDGAR): Version 2.0., in Climate Research: Evaluation and Policy Implication-Proceedings of the International Climate Change Research Conference, Maastricht, The Netherlands, edited by S. Zwerver et al., pp. 651-669, Elsevier, New York.

Paustian, K., J. Six, E. T. Elliott, and H. W. Hunt (2000), Management options for reducing $\mathrm{CO}_{2}$ emissions from agricultural soils, Biogeochemistry, 48, 147-163.

Pointing, C. (1991), A Green History of the World: The Environment and the Collapse of Great Civilizations, St. Martin's, New York.

Ramankutty, N., and J. Foley (1998), Characterizing patterns of global land use: An analysis of global croplands data, Global Biogeochem. Cycles, $12,667-685$ 
Randerson, J. T., M. V. Thompson, T. J. Conway, I. Y. Fung, and C. B. Field (1997), The contribution of terrestrial sources and sinks to trends in the seasonal cycle of atmospheric carbon dioxide, Global Biogeochem. Cycles, 11, 535-560.

Rödenbeck, C., S. Houweling, M. Gloor, and M. Heimann (2003), $\mathrm{CO}_{2}$ flux history 1982-2001 inferred from atmospheric data using a global inversion of atmospheric transport, Atmos. Chem. Phys. Disc., 3, 2575-2659.

U.S. Department of Agriculture (2000), Agricultural Statistics 2000, United States Gov. Print. Off., Washington, D. C. (Available at http://www.usda. gov/nass/pubs/agr00/acro00.htm)
Vitousek, P. M., P. Ehrlich, A. Ehrlich, and P. M. Matson (1986), Human appropriation of the products of photosynthesis, Bioscience, 36, 368373.

P. Bousquet and P. Ciais, Laboratoire des Sciences du Climat et de l'Environnement, CE Orme des Merisiers, F-91191 Gif sur Yvette, France. (philippe.ciais@cea.fr)

A. Freibauer, Max-Planck-Institute for Biogeochemistry, PF 100164, D-07701 Jena, Germany.

T. Naegler, Institut für Umweltphysik, Universität Heidelberg, D-69120 Heidelberg, Germany. 